This item was submitted to Loughborough's Research Repository by the author.

Items in Figshare are protected by copyright, with all rights reserved, unless otherwise indicated.

\title{
FTIR analysis of silane grafted high density polyethylene
}

PLEASE CITE THE PUBLISHED VERSION

PUBLISHER

(C) Maney Publishing

VERSION

VoR (Version of Record)

LICENCE

CC BY-NC-ND 4.0

REPOSITORY RECORD

Ahmed, Gulshan S., Marianne Gilbert, S. Mainprize, and M. Rogerson. 2009. "FTIR Analysis of Silane Grafted High Density Polyethylene". figshare. https://hdl.handle.net/2134/4504. 
This item was submitted to Loughborough's Institutional Repository (https://dspace.lboro.ac.uk/) by the author and is made available under the following Creative Commons Licence conditions.

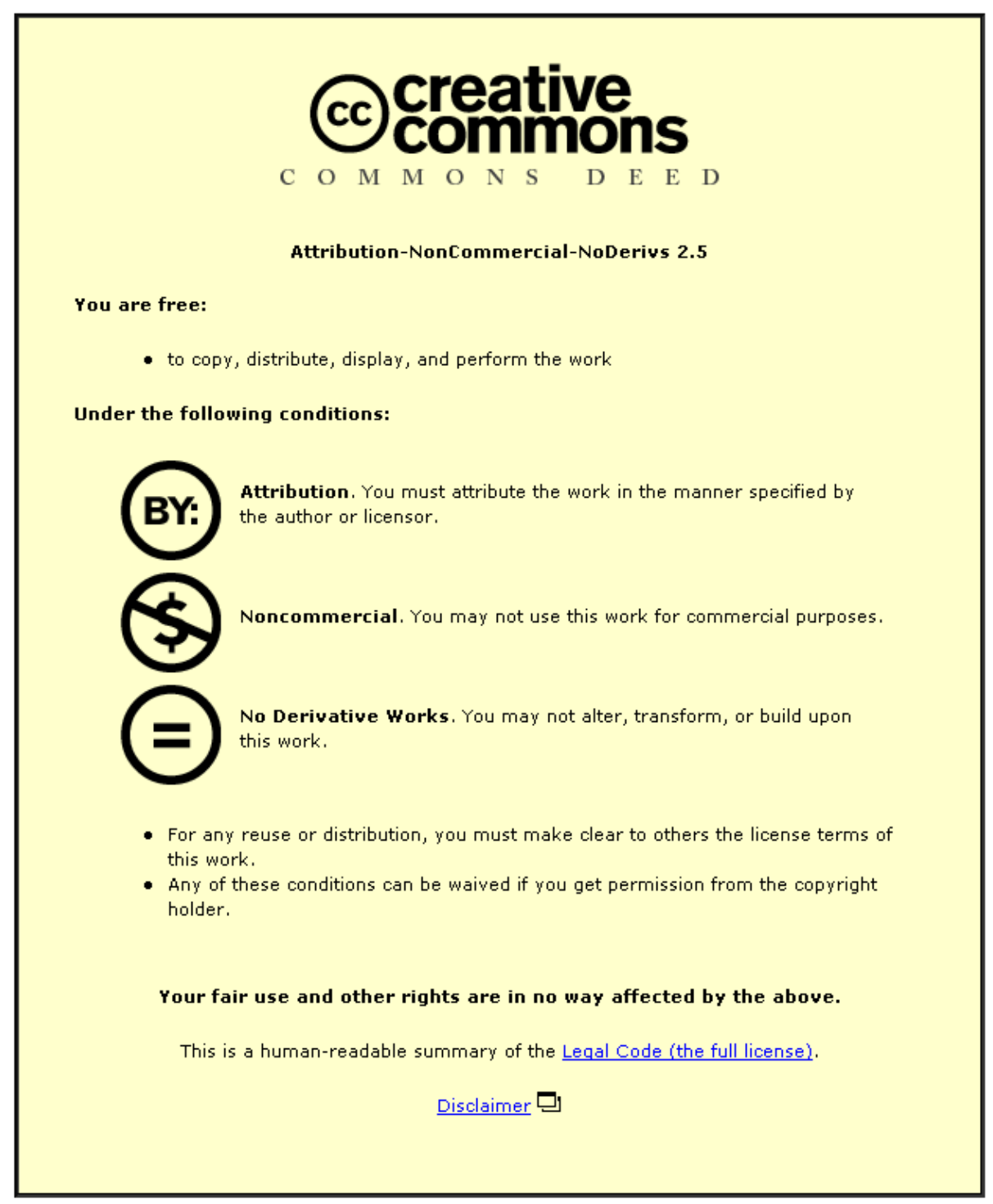

For the full text of this licence, please go to: http://creativecommons.org/licenses/by-nc-nd/2.5/ 


\title{
FTIR analysis of silane grafted high density polyethylene
}

\author{
G. S. Ahmed ${ }^{1}$, M. Gilbert*1, S. Mainprize ${ }^{2}$ and M. Rogerson ${ }^{2}$
}

Vinyltrimethoxysilane (VTMOS) monomer was grafted onto high density polyethylene by reactive processing in a twin screw extruder in the temperature range of $180-240^{\circ} \mathrm{C}$. The effect of VTMOS and 1,3-bis (tert-butylperoxyisopropyl) benzene peroxide (BTBB) on the extent of grafting was studied using qualitative and quantitative Fourier transform infrared spectroscopy. The grafting reactions were confirmed via infrared absorption bands present in the $800 \mathrm{~cm}^{-1}$ region which are characteristic wavenumbers for the vibration modes of the Si-CH group from VTMOS $\left(\mathrm{CH}_{2}=\mathrm{CH}\right.$ $\left.\mathrm{Si}-\left(\mathrm{OCH}_{3}\right)_{3}\right)$. The percentage of reacted and unreacted VTMOS was calculated by a novel Fourier transform infrared spectroscopy quantitative method developed through measurements of infrared absorbance bands at peaks 795 and $814 \mathrm{~cm}^{-1}$ that are influenced by both reacted and unreacted silane. The effect of silane and peroxide concentrations on the concentration of reacted and unreacted silane present in the material was determined. The change in unsaturation content measured at absorbance $1009 \mathrm{~cm}^{-1}$ supported these findings.

Keywords: Polyethylene, Silane grafting, Infrared analysis

\section{Introduction}

Polyolefins are a family of commercial thermoplastic polymers. Polyethylene is the most important in terms of commercial applications employed to produce wire and cables, plastic pipes, etc. ${ }^{1}$

The cross-linking of polyethylene drastically improves the material properties such as creep behaviour, thermal performance and higher impact and chemical resistance. $^{2,3}$ There are a variety of ways to cross-link polyethylene. ${ }^{4}$ The three main cross-linking methods that are of commercial interest involve radiation crosslinking, peroxide cross-linking and silane cross-linking. ${ }^{5}$ The latter technique that involved cross-linking with organofunctional silane developed through the Sioplas ${ }^{6,7}$ and Monosil ${ }^{8,9}$ processes has been used successfully since the 1970 s, and has gained great attention in recent years because of its advantages compared with radiation and peroxide cross-linking. The advantages of using the silane grafted polymer are easy processing, low cost and capital investment and also better properties of the cross-linked materials.

The process of making cross-linkable polyethylene with organosilane involves melt grafting in an extruder reactor $^{10-15}$ of the unsaturated silane polar groups onto the polymer backbone in the presence of a free radical initiator. The most commonly used silane for manufacturing cross-linkable polyethylene is vinyltrimethoxysilane

${ }^{1}$ Institute of Polymer Technology and Material Engineering, Loughborough University, Loughborough, Leicestershire, LE11 3TU, UK

${ }^{2}$ Micropol Limited, Bayley street, Stalybridge, Cheshire, SK15 1QQ, UK

*Corresponding author, m.gilbert@lboro.ac.uk
(VTMOS). ${ }^{13,15}$ In the first stage the peroxide, VTMOS and polyethylene are all compounded in a twin screw extruder at high temperatures to produce the graft copolymer. Initially the peroxide decomposes to form free radicals. These radicals then abstract hydrogen atoms from the polyethylene backbone to generate radical sites onto which the VTMOS is attached. In the second stage the graft copolymers are hydrolysed and cross-linked by forming Si-O-Si linkages under treatment with water in the presence of a suitable catalyst. Hjertberg and coworkers ${ }^{16}$ studied the kinetics of cross-linking reactions of VTMOS graft copolymer.

Shieh and $\mathrm{Liu}^{17}$ studied the silane (vinyltriethoxysilane and VTMOS) grafting reactions of low density polyethylene (LDPE), high density polyethylene (HDPE) and linear low density polyethylene (LLDPE) and Shieh and $\mathrm{Tsai}^{18}$ studied the silane (VTMOS) grafting reactions of low density polyethylene. These studies concentrated on Fourier transform infrared spectroscopy (FTIR) qualitative analysis to identify the main peaks that are characteristic for the alkoxy groups (Si-O-C) and to determine quantitatively the effect of silane and peroxide on the extent of silane grafting reactions. Other characterisation techniques were also used for grafting analysis. Detailed quantitative studies in the $800 \mathrm{~cm}^{-1}$ region have not been carried out on VTMOS grafted HDPE previously.

Fourier transform infrared spectroscopy is the most widely used technique for determining degree of grafting both quantitatively and qualitatively. ${ }^{18-24}$

The main focus in this paper is to produce a graft copolymer and then qualitatively and quantitatively analyse the graft copolymer in the first stage of the grafting reaction. This will also include investigating the 
effect the concentration of additives (VTMOS and peroxide) has on the grafting level.

\section{Experimental}

\section{Materials}

High density polyethylene was supplied by BP Chemicals Limited (now Ineos) under the trade name BP RIGIDEX HDPE (PC4017). The unsaturated polar monomer, VTMOS, shown below, and used as a grafting agent for polymers is a standard laboratory reagent supplied under the trade name Silquest A-171 Silane from Witco (Europe) SA (organosilicones group).<smiles>C=C[Si](OC)(OC)OC</smiles>

1,3-bis (tert-butylperoxyisopropyl) benzene, trade name Perkadox $14 \mathrm{~s}$, supplied by Akzo Nobel Limited was used as the free radical peroxide initiator. A recommended mixture of phenolic and phosphate type antioxidants were selected and purchased from CIBA speciality chemicals PLC were used. All the chemicals were used as received. Also octyltrimethoxysilane (96\%) was used as received from Sigma- Aldrich; this was used as a model compound for a grafted VTMOS copolymer.

\section{Preparation of VTMOS grafted polyethylene}

Vinyltrimethoxysilane was grafted onto HDPE using an APV MP-30TC co-rotating twin screw compounding extruder. The extruder had a screw diameter of $30 \mathrm{~mm}$ and a length/diameter ratio of $30: 1$. The screw speed was set at a constant mixing speed of $250 \mathrm{rev} \mathrm{min}^{-1}$ and the extruder was maintained at temperatures ranging from $180^{\circ} \mathrm{C}$ at the feeding zone to $200^{\circ} \mathrm{C}$ at the metering zone to $240^{\circ} \mathrm{C}$ at the die zone.

Initially the raw materials (HDPE pellets, the antioxidants and the peroxide), were mixed thoroughly in a polyethylene bag for 2-3 min. This was followed by adding the VTMOS and the mixing was continued for a further 1 min until all the granules were fully coated.

The coated granules were then loaded into the extruder hopper and extruded through a two hole die. The extrudates were passed through a water bath, fan dried and granulated.

The extruded granules were dried in an oven at a temperature of $50^{\circ} \mathrm{C}$ for one hour, to remove any moisture remaining on the granules. The samples were

Table 1 Formulation of VTMOS grafted polyethylene, wt-\%

\begin{tabular}{lll}
\hline Sample & VTMOS & BTBB \\
\hline A & 0 & 0.050 \\
B & 1.400 & 0.050 \\
C & 1.600 & 0.050 \\
D & 1.800 & 0.050 \\
E & 2.000 & 0.050 \\
F & 2.200 & 0.050 \\
G & 1.800 & 0 \\
H & 1.800 & 0.010 \\
I & 1.800 & 0.030 \\
J & 1.800 & 0.050 \\
K & 1.800 & 0.070 \\
L & 1.800 & 0.090 \\
\hline
\end{tabular}

then sealed in aluminium bags to prevent premature cross-linking in the presence of atmospheric moisture.

Two series of grafted samples were processed. The composition of the reaction recipe was typically $2 \mathrm{~kg}$ of HDPE which remained constant. In the first series the component VTMOS varied $0 \cdot 0-2 \cdot 2 \mathrm{wt}-\%$ with the BTBB concentration constant at $0.05 \mathrm{wt}-\%$ (samples $\mathrm{A}-\mathrm{F})$. In the second series the BTBB was varied $0 \cdot 0$ 0.09 wt- $\%$ with the VTMOS kept constant at $1.80 \mathrm{wt}-\%$ (samples G-L). Table 1 shows concentration variations used in processing the grafted samples.

\section{Analysis and characterisation}

\section{Fourier transform infrared spectroscopy \\ Samples prepared for qualitative analysis}

To obtain infrared spectra a Mattson 3000 FTIR spectrometer was used. Samples were prepared by melt pressing to obtain thin films $(\sim 0.2 \mathrm{~mm}$ thick $)$ by compression moulding $0 \cdot 1-0.2 \mathrm{~g}$ polymer granules between Melinex sheets. The films were placed into a hot press under a load of 10 tonne at a temperature of $160^{\circ} \mathrm{C}$ for less than 4 min to avoid cross-linking. They were then cooled in a cold press for $1 \mathrm{~min}$.

The thin films were held by two magnets on a sample holder and then scanned by passing a single beam through the material; the spectrum was scanned over a range of $600-4000 \mathrm{~cm}^{-1}$.

\section{Samples prepared for quantitative analysis}

In order to construct calibration graphs for quantitative analysis a series of VTMOS and octyltrimethoxysilane concentrated standards $\left(0.0025\right.$ to $0.04 \mathrm{~g} \mathrm{~L}^{-1}$ or $0 \cdot 28 \times 10^{-3}$ to $4 \cdot 49 \times 10^{-3}$ wt- $\%$ ) were prepared in tetrahydrofuran at room temperature. The solutions were injected between two sodium chloride plates with a constant $(0.05 \mathrm{~mm})$ spacer thickness that was held in a Specac Omni cell holder to prepare the samples for FTIR analysis.

Fourier transform infrared spectroscopy analysis for the quantitative analysis was carried out on these standards using an 8300 Shimadzu spectrometer with a resolution of $1 \mathrm{~cm}^{-1}$, and a total of 10 scans on average over a range $600-4000 \mathrm{~cm}^{-1}$.

\section{Results and discussion}

\section{Evidence of grafting \\ Effect of VTMOS concentration}

To ensure that VTMOS grafting had occurred during the processing FTIR spectroscopy was performed on both the HDPE homopolymer and the modified HDPE, reacted with various amounts of VTMOS (0-2.2 wt- $\%)$ and $0.05 \mathrm{wt}-\%$ BTBB. These spectra are compared in Fig 1. Table 2 shows the main peak assignments in VTMOS and polyethylene.

There are strong characteristic absorption peaks that are assigned to the silane carbon bonds, $\mathrm{Si}-\mathrm{CH}$ at 773 and $816 \mathrm{~cm}^{-1}$ and absorption peaks at 1192 and $1092 \mathrm{~cm}^{-1}$ characteristic of the methoxy groups Si-O$\mathrm{CH}_{3}$ and any siloxane cross-links (Si-O-Si) that are formed during the extrusion. Also, the presence of the vinyl group in silane appears in the curves $\mathrm{B}-\mathrm{F}$, changes of shape in the $800 \mathrm{~cm}^{-1}$ region indicating that silane grafting reactions have occurred. The peak intensities at 1092 and $1192 \mathrm{~cm}^{-1}$ start to increase, this corresponds 


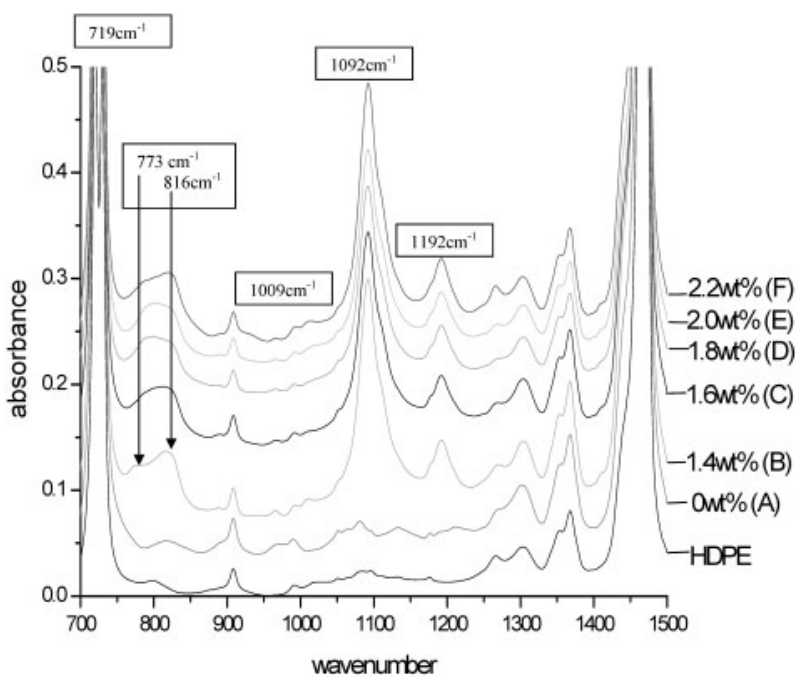

1 Fourier transform infrared spectra of silane grafted polyethylene with varying VTMOS concentration

to an increase in the quantity of Si-O-C bonds because more VTMOS is present.

The peaks at 1092 and $1192 \mathrm{~cm}^{-1}$ were also used to measure the relative amount of silane grafting $R .^{11,16,20}$ This was determined by measuring the area of the absorption peaks of the $\mathrm{Si}-\mathrm{O}-\mathrm{CH}_{3}$ groups and calculating the ratio of these peaks with respect to the absorbance peak at $719 \mathrm{~cm}^{-1}$ due to $\left(-\mathrm{CH}_{2}-\right)_{\mathrm{n}}$ that is chosen to be the internal reference of the polyethylene (remains unchanged during the grafting reactions).

$$
R=A_{1092} / A_{719}
$$

The relationship between increase in VTMOS and R can be seen in Figs. 2 and 3. The absorbance peak at $1192 \mathrm{~cm}^{-1}$ increases with VTMOS concentration indicating that excess amounts of unreacted VTMOS groups were present. However, according to the Beer Lambert law $A=\varepsilon c l$ (where $A$ is the absorbance of a given vibration, $\varepsilon$ represents the extinction coefficient, $l$ the thickness of the film and $c$ the concentration of the vibrating group) this graph should be linear. Assuming all the silane reacted for the sample material with the lowest concentration of silane, a constant was calculated where

$$
\frac{A_{1}}{A_{2}}=\frac{\varepsilon_{1} C_{1}}{\varepsilon_{2} C_{2}}
$$

In this case $\frac{A_{1}}{A_{2}}$ corresponds to absorbance peak ratio value $\mathrm{R}$ for a given sample and $\frac{C_{1}}{C_{2}}$ corresponds to

Table 2 Peak position assignments

\begin{tabular}{lll}
\hline Wavenumber, $\mathbf{c m}^{-\mathbf{1}}$ & Group & Remark \\
\hline 1192 & $\mathrm{Si}-\mathrm{O}-\mathrm{C}$ & $\mathrm{O}-\mathrm{CH}_{3}$ rocking vibration \\
1092 & $\mathrm{Si}-\mathrm{O}-\mathrm{C}$ & $\mathrm{O}-\mathrm{C}$ stretching vibration of reacted or unreacted silane \\
$1009 / 992$ & $\mathrm{CH}=\mathrm{CH}-\mathrm{Si}$ & Vinyl chain group \\
$1087 / 1020$ & $\mathrm{Si}-\mathrm{O}-\mathrm{Si}$ & $\mathrm{Si}-\mathrm{O}-\mathrm{Si}$ vibration \\
$1130 / 1000$ & $\mathrm{Si}-\mathrm{O}-\mathrm{Si}$ & $\mathrm{Si}-\mathrm{O}-\mathrm{Si}$ asymmetric stretching \\
815 & $\mathrm{Si}-\mathrm{O}-\mathrm{CH}_{3}$ & $\mathrm{Si}-\mathrm{O}-\mathrm{CH}_{3}$ stretching \\
$771-795$ & $\mathrm{Si}-\mathrm{O}-\mathrm{CH}_{3}$ & $\mathrm{Si}-\mathrm{O}-\mathrm{CH}_{3}\left(\mathrm{CH}_{3}\right.$ rocking) \\
1367 & $\mathrm{C}-\mathrm{CH}_{2}$ & Symmetric bending of C-H bond \\
$1445-1465$ & $\mathrm{C}-\mathrm{CH}_{2}$ & $\mathrm{CH} \mathrm{H}_{2}$ wagging (asymmetric bending vibration) \\
$710-730$ & $\mathrm{C}-\mathrm{CH}_{2}$ & $\mathrm{CH} \mathrm{H}_{2}$ rocking vibration \\
2850 & $\mathrm{CH}_{2}$ & Symmetric C-H stretch \\
2919 & $\mathrm{CH}_{2}$ & Asymmetric C-H stretch
\end{tabular}

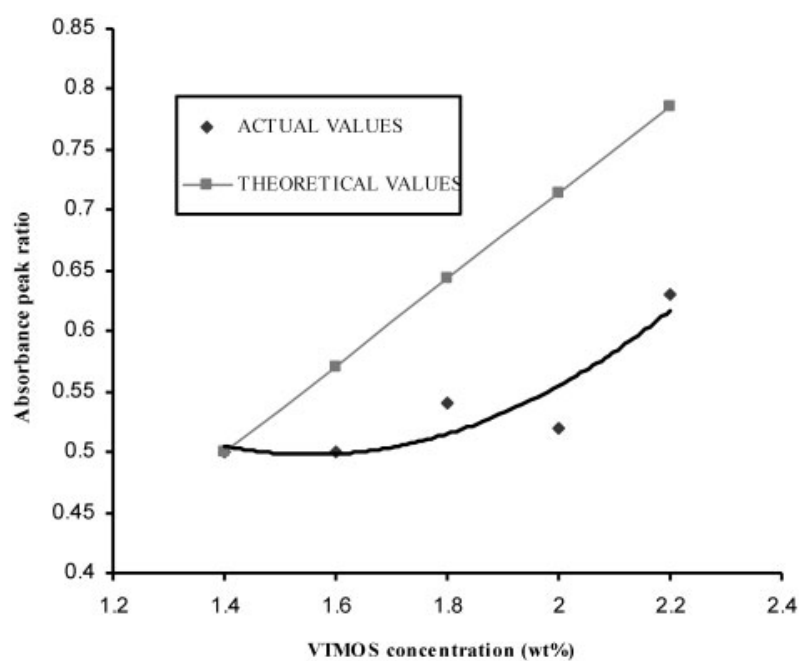

2 Effect of VTMOS concentrations on absorbance peak ratio at $1092 \mathrm{~cm}^{-1}$

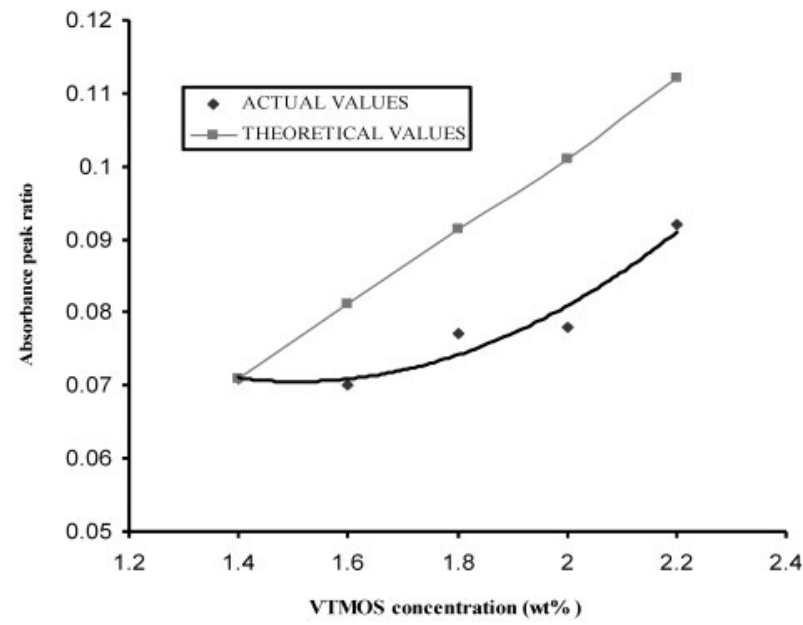

3 Effect of VTMOS concentrations on absorbance peak ratio at $1192 \mathrm{~cm}^{-1}$

concentrations of silane $\mathrm{C} 1$ with respect to concentration of polyethylene C2. Since C2 is constant for all the samples, therefore, $\frac{A_{1}}{A_{2}}=K C_{1}$ in which $K$ was to be considered as a constant for all the samples in the series. The theoretical $\mathrm{R}$ values for the other grafted samples was calculated accordingly using $\frac{A_{1}}{A_{2}}=K C_{1}$ and $\mathrm{Cl}$ being the concentration of silane for that particular sample. From the results the difference between the theoretical and actual (calculated directly from FTIR 


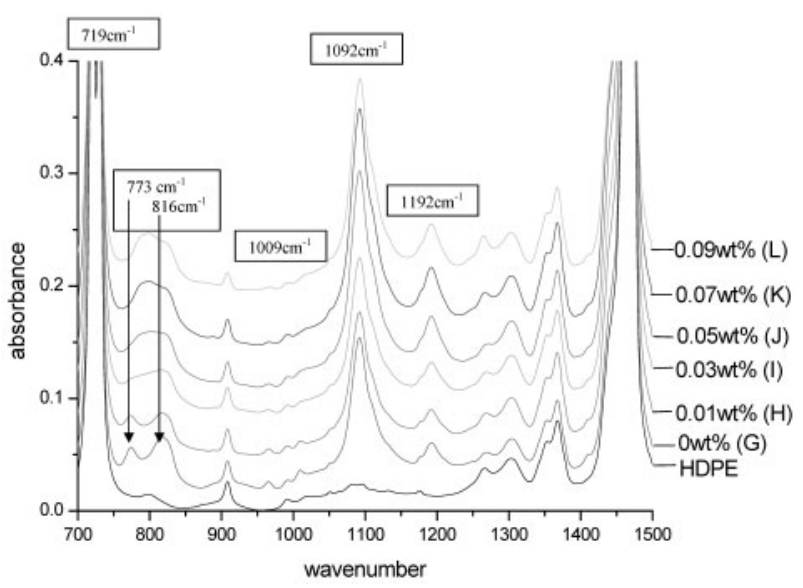

4 Fourier transform infrared spectra of silane grafted polyethylene with varying peroxide concentration

spectra) $R$ values showed that there is a loss in VTMOS during the processing of the samples.

These methoxysilane peaks were selected as they show the strongest absorbance peaks however, the peak at $1092 \mathrm{~cm}^{-1}$ is not very reliable since it is also characteristic for the absorbance of the siloxane $\mathrm{Si}-\mathrm{O}-\mathrm{Si}$ groups that may form during the processing stage due to small traces of moisture from the atmosphere or in the presence of oxygen (oxidative silane cross-linking reactions). ${ }^{20}$ This will therefore influence the absorbance values of $\mathrm{Si}-\mathrm{O}-\mathrm{CH}_{3}$.

\section{Effect of peroxide concentration}

Studies ${ }^{25}$ using FTIR have been carried out to measure the amount of silane grafted onto different polyethylenes (HDPE, LDPE and LLDPE). It was proposed that the absorption peak at $1092 \mathrm{~cm}^{-1}$ that corresponds to the $\mathrm{Si}-\mathrm{O}-\mathrm{C}$ stretching vibration of the silane group is related to the silane grafted onto the polyethylene. From the study it was concluded that LLDPE and LDPE have similar amounts of silane grafting while HDPE has a much lower silane grafting efficiency. Overall few studies have been conducted on VTMOS grafted HDPE. However, studies ${ }^{26}$ that have been carried out on LDPE show that peaks present at 1092 and $1192 \mathrm{~cm}^{-1}$ are assigned to functional groups $\mathrm{Si}-\mathrm{O}-\mathrm{CH}_{3}$ and are attributed to silane grafted onto the polyethylene. There is a relative increase in the extent of VTMOS grafting with an increase in VTMOS concentration.

Figure 4 shows the effect of peroxide concentration on the VTMOS grafting polyethylene reactions. As for the first series of grafted samples FTIR spectroscopy was performed to ensure grafting had occurred and to

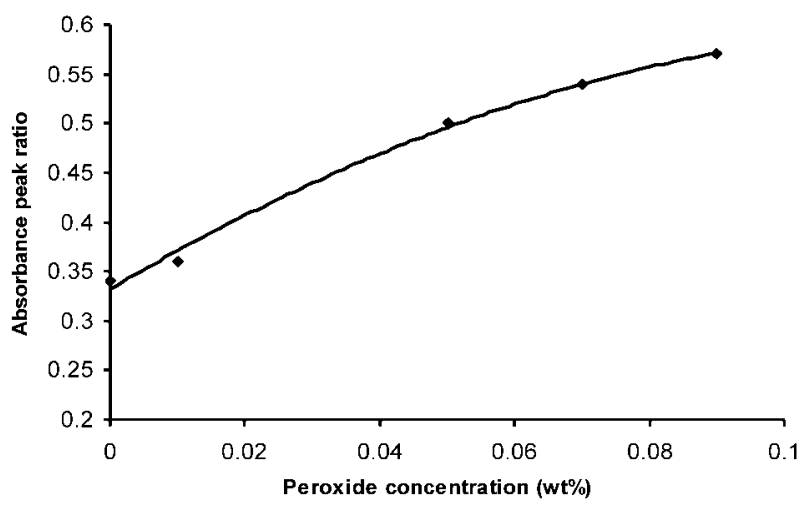

5 Effect of peroxide concentration on absorbance peak ratio at $1092 \mathrm{~cm}^{-1}$

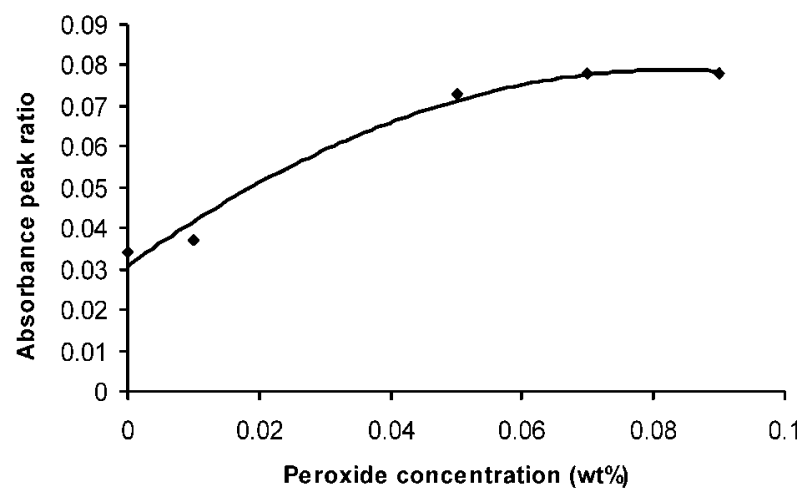

6 Effect of peroxide concentration on absorbance peak ratio at $1192 \mathrm{~cm}^{-1}$

see what effect the peroxide has on the grafting level. In this series of samples the BTBB concentration was varied from $0-0.09 \mathrm{wt}-\%$ with the VTMOS concentration remaining constant at $1.8 \mathrm{wt}-\%$. From the FTIR spectra it can be seen that the peaks characteristic for the silane Si-CH groups at 773 and $816 \mathrm{~cm}^{-1}$, the methoxy $\mathrm{Si}-\mathrm{O}-\mathrm{CH}_{3}$ at 1092 and $1192 \mathrm{~cm}^{-1}$ and the vinyl group of silane appear in curves $\mathrm{G}-\mathrm{L}$.

There is also an increase in the relative amount $R$ of VTMOS with an increase in peroxide concentration although the VTMOS concentration is constant, as can be seen in Figs. 5 and 6.

With zero and low concentrations of peroxide (samples $\mathrm{G}$ and $\mathrm{H}$ ) $R$ is lower than the $R$ value for sample $\mathrm{D}$ from the first series of samples. This is due to a loss of VTMOS by volatilisation because there is excess VTMOS, whereas with higher concentrations of peroxide ( $\mathrm{J}, \mathrm{K}$ and $\mathrm{L})$ there is less loss, because all the silane could have reacted more quickly. This can be explained by the fact that with increase in peroxide concentration there are more radical sites present and therefore less VTMOS is lost.

The increase in $R$ can also be partly attributed to an overlap of Si-O- $\mathrm{CH}_{3}$ groups and $\mathrm{Si}-\mathrm{O}-\mathrm{Si}$ groups at 1092 and $1192 \mathrm{~cm}^{-1}$. Therefore with a constant concentration of VTMOS some of the $\mathrm{Si}-\mathrm{O}-\mathrm{CH}_{3}$ groups have formed $\mathrm{Si}-\mathrm{O}-\mathrm{Si}$ groups, showing an increase with an increase in peroxide concentration. This overlap can be seen clearly in Fig. 7 displaying FTIR spectra of a grafted and a cross-linked polyethylene sample from both series.

\section{Quantitative analysis}

An analysis method was developed to quantify the percentage of reacted and unreacted VTMOS on the polyethylene using two absorption peaks in the $800 \mathrm{~cm}^{-1}$ region of the FTIR spectrum of each grafted sample.

Fourier transform infrared was used to observe and investigate the changes in the peaks around the $800 \mathrm{~cm}^{-1}$ region where the silane $\mathrm{Si}-\mathrm{CH}$ groups absorb. A single broad peak at $\sim 800 \mathrm{~cm}^{-1}$ due to $-\mathrm{Si}-\mathrm{CH}$ indicates efficient grafting and two peaks (doublet) at 771 and $814 \mathrm{~cm}^{-1}$ attributed respectively to the unreacted Si$\mathrm{CH}=\mathrm{CH}_{2}$ rocking and stretching modes indicate the presence of free VTMOS, where the VTMOS has not grafted correctly onto the polyethylene. ${ }^{27}$

The infrared spectrum of sample $\mathrm{H}$ showing doublet peaks was subtracted from that of sample L showing a broad single peak (as seen in Fig. 4), in an attempt to remove unreacted VTMOS.

As a result of the subtraction it was noticed that two peaks at 795 and $833 \mathrm{~cm}^{-1}$ remained. These are related 


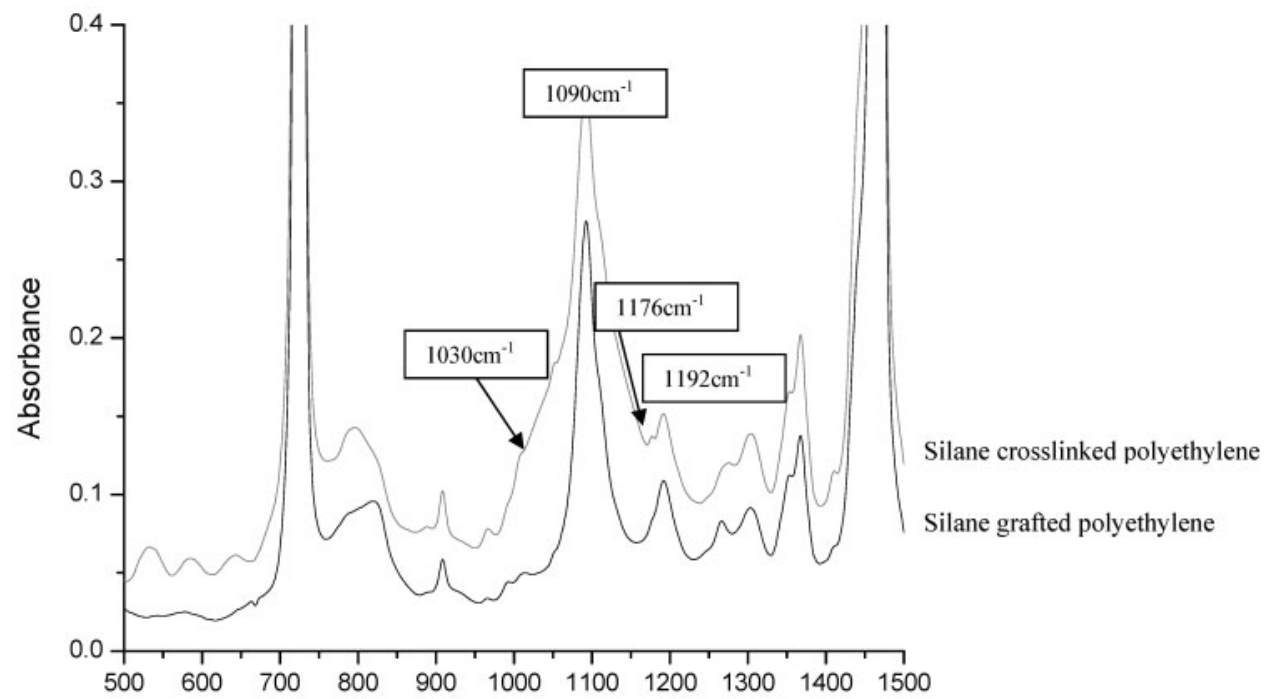

Wavenumber

\section{Fourier transform infrared spectra of silane grafted and silane cross-linked polyethylene}

to fully reacted VTMOS. Therefore it was concluded that when polyethylene is reacted with VTMOS a broad single peak is composed of a possible total of four peaks that overlap with each other (two peaks contributing to the unreacted VTMOS and two peaks for the reacted VTMOS). This can be seen in Fig. 8.

Calibration graphs were prepared using the standard solutions of VTMOS and octyltrimethoxysilane (used as a model compound for a fully reacted sample). The two absorbance peaks in the region of interest $\left(800 \mathrm{~cm}^{-1}\right.$ region) for VTMOS are 771 and $814 \mathrm{~cm}^{-1}$, while octyltrimethoxysilane has a broad peak from 795 to $833 \mathrm{~cm}^{-1}$, as shown in Figs. 9 and 10, which show expansions of the $800 \mathrm{~cm}^{-1}$ region inset. The peak heights for the maximum peaks were used in both the VTMOS $\left(814 \mathrm{~cm}^{-1}\right)$ and octyltrimethoxysilane $\left(795 \mathrm{~cm}^{-1}\right)$ and were measured using the FTIR software to construct the calibration graphs. Any interference between the reacted and unreacted VTMOS at $814 \mathrm{~cm}^{-1}$, and at $795 \mathrm{~cm}^{-1}$ was noted.

Figure 9 shows that no significant absorption occurred at $795 \mathrm{~cm}^{-1}$ in the VTMOS standard spectrum. Therefore there is no interference between the peak at $795 \mathrm{~cm}^{-1}$ and the unreacted peak at $814 \mathrm{~cm}^{-1}$. As a result of this, the peak height at $795 \mathrm{~cm}^{-1}$ can be used to monitor the concentration of reacted silane directly.

Octyltrimethoxysilane shows a broad peak in the $800 \mathrm{~cm}^{-1}$ region as shown in Fig. 10, therefore similar absorbance is observed at 795 and $814 \mathrm{~cm}^{-1}$.

Using the Beer-Lambert law $(A=\varepsilon c l)$ the extinction coefficient was calculated for the absorbance peaks at 795 and $814 \mathrm{~cm}^{-1}$ for both the silane and octyltrimethoxysilane. The absorbance at $795 \mathrm{~cm}^{-1}$ will contribute only to the reacted silane at $795 \mathrm{~cm}^{-1}$ whereas the absorbance at $814 \mathrm{~cm}^{-1}$ corresponds to both the reacted and unreacted silane at $814 \mathrm{~cm}^{-1}$. The extinction coefficient

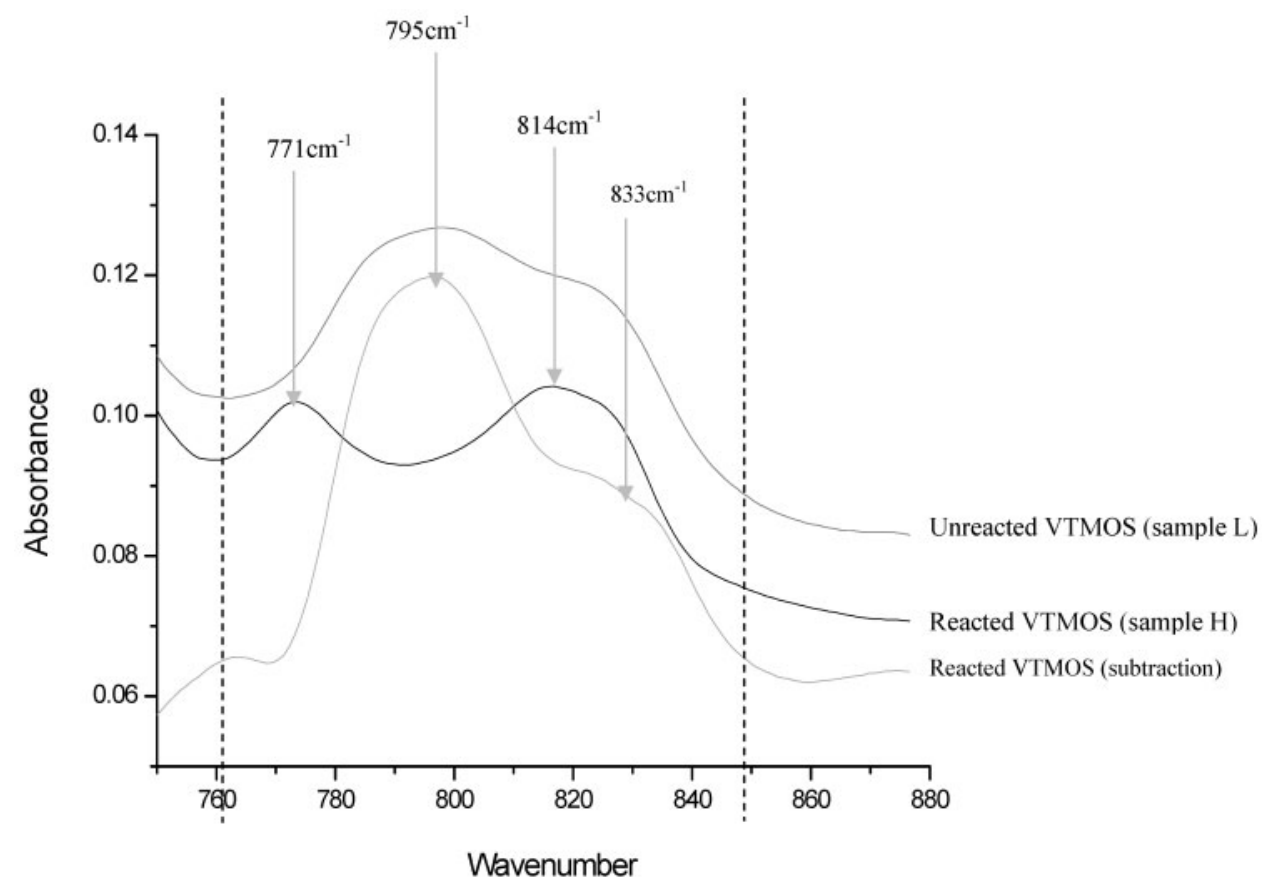

8 Fourier transform infrared spectra showing peak overlaps 


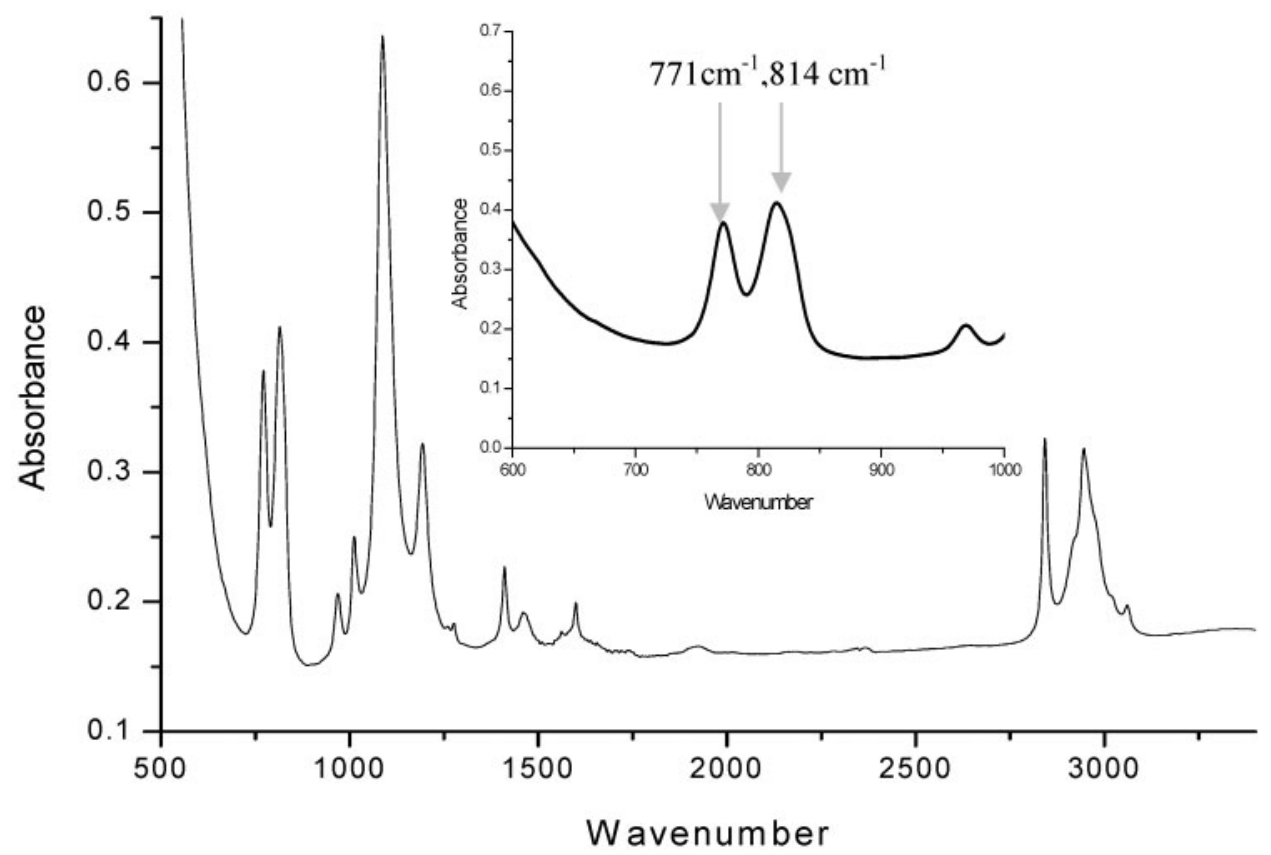

\section{Fourier transform infrared spectrum of VTMOS}

value for the VTMOS absorbance peak at $814 \mathrm{~cm}^{-1}$ was found to be $263 \cdot 40 \mathrm{wt}-\%^{-1} \mathrm{~mm}^{-1}$.

The extinction coefficient value for the octyltrimethoxysilane, at both wavelengths 795 and $814 \mathrm{~cm}^{-1}$ was calculated to be $62.59 \mathrm{wt}-\%^{-1} \mathrm{~mm}^{-1}$.

Further calculations were conducted to establish a method that was used to obtain the concentration of reacted and unreacted VTMOS in a sample processed on the extruder, which would be applicable to any VTMOS grafted HDPE samples processed on the extruder.

Taking into account both the absorbance peaks at 795 and $814 \mathrm{~cm}^{-1}$, the following applies.

$$
\begin{aligned}
& A_{795}=\varepsilon_{795 \mathrm{R}} C_{\mathrm{R}} l \\
& A_{814}=\varepsilon_{814 \mathrm{R}} C_{\mathrm{R}} l+\varepsilon_{814 \mathrm{U}} C_{\mathrm{U}} l
\end{aligned}
$$

where $C_{\mathrm{R}}$ is concentration reacted silane and $C_{\mathrm{U}}$ is concentration unreacted silane

After dividing equation (1) by (2) to eliminate thickness, and substituting the calculated values for extinction coefficients it can be shown that

$$
\frac{A_{795}}{A_{814}}=\frac{1}{1+4 \cdot 2 \frac{C_{\mathrm{U}}}{C_{\mathrm{R}}}}
$$

Even if VTMOS was lost during the processing of the samples it did not affect the calculated percentage concentration of reacted and unreacted VTMOS in the grafted samples, since concentration ratios are used in equation (3).

Equations (1)-(3), were used to calculate the concentration of reacted and unreacted VTMOS in the VTMOS grafted polyethylene samples processed on the extruder.

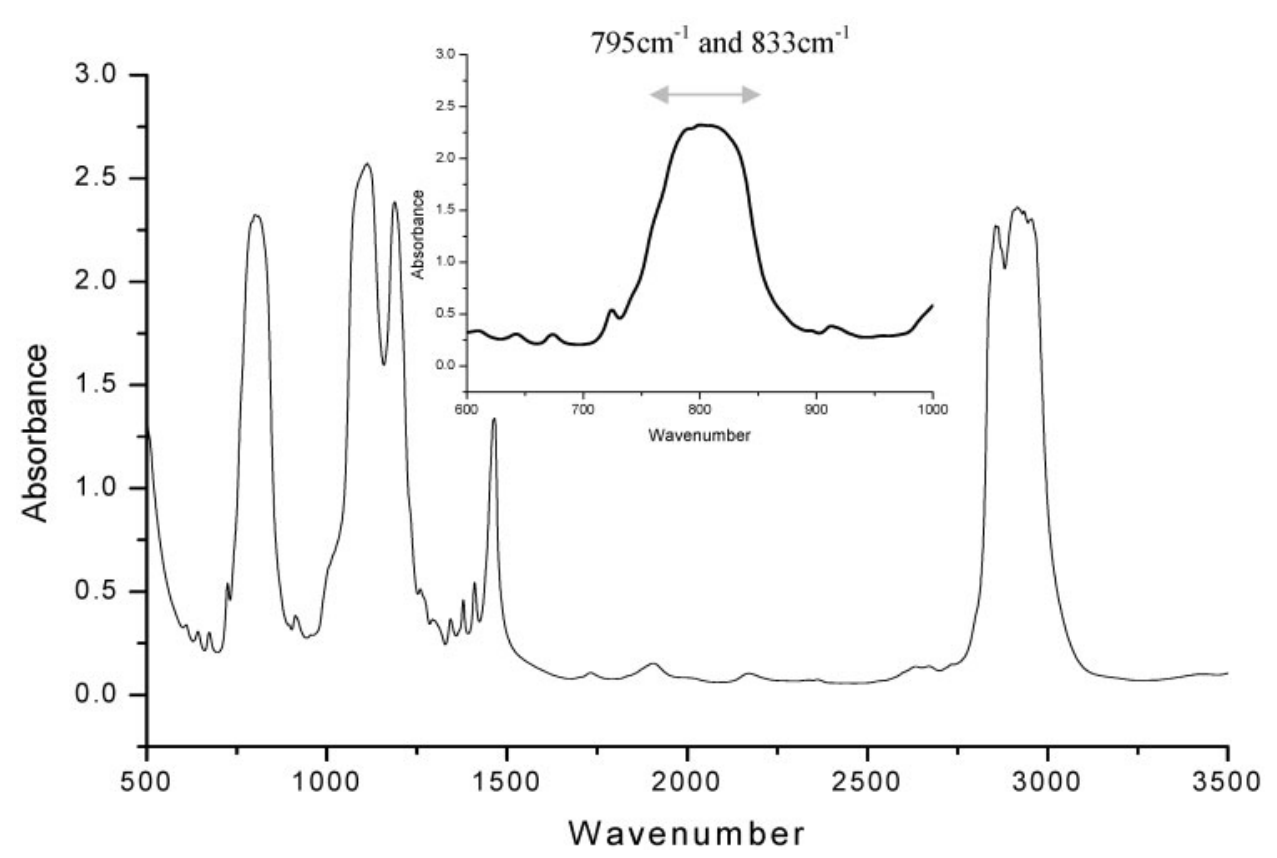

10 Fourier transform infrared spectrum of octyltrimethoxysilane 


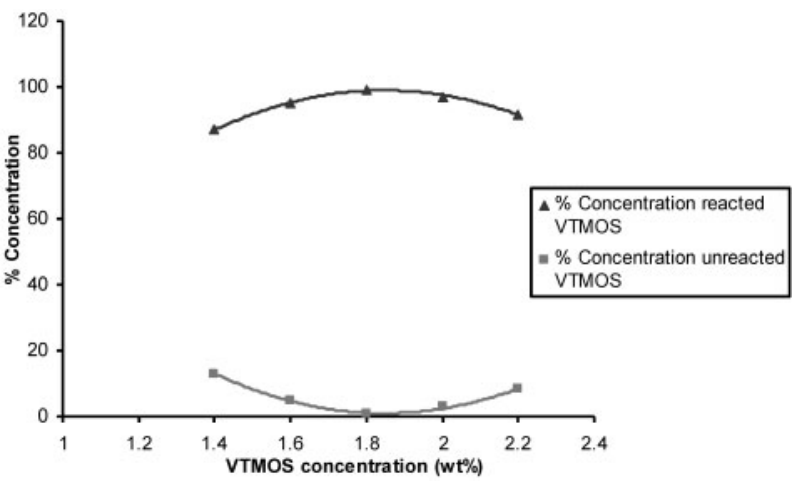

11 Effect of VTMOS (wt-\%) on percentage concentration reacted and unreacted VTMOS

Rearranging equation (3)

$C_{\mathrm{U}}=\left(\frac{1-X}{4 \cdot 2 X}\right) C_{\mathrm{R}}$

where

$$
X=\frac{A_{795}}{A_{814}}
$$

Therefore

$$
C_{\mathrm{U}}=n C_{\mathrm{R}}
$$

where

$$
n=\frac{1-X}{4 \cdot 2 X}
$$

Then substituting equation (5) into equation (4) and rearranging.

$$
\% C_{\mathrm{R}}=\frac{1}{1+n} \times 100
$$

Equation (6) was applied to all the samples processed in both series (samples A-L) to calculate the concentrations of reacted and unreacted VTMOS. (These figures relate the unreacted silane present in the grafted samples. Some silane will have been lost by volatilisation during processing (see Figs. 2 and 3), while some of the reacted silane will have formed low molar mass byproducts rather than polymer. This will be considered in a future paper.)

Table 3 shows the ratio of the two peak heights and Fig. 11 illustrates the relationship between the percentage concentrations of reacted and unreacted VTMOS

Table 3 Ratio of absorbance peaks in VTMOS grafted polyethylene samples

$$
\mathrm{X}
$$

\begin{tabular}{lll}
\cline { 2 - 3 } Sample & $\mathrm{A} 795 \mathrm{~cm}^{-\mathbf{1}} / \mathrm{A} 814 \mathbf{c m}^{-\mathbf{1}}$ & $C_{U}$ \\
\hline $\mathrm{A}$ & - & - \\
$\mathrm{B}$ & 0.61 & $0.15 C_{\mathrm{R}}$ \\
$\mathrm{C}$ & 0.82 & $0.05 C_{\mathrm{R}}$ \\
$\mathrm{D}$ & 0.97 & $0.007 C_{\mathrm{R}}$ \\
$\mathrm{E}$ & 0.88 & $0.03 C_{\mathrm{R}}$ \\
$\mathrm{F}$ & 0.72 & $0.091 C_{\mathrm{R}}$ \\
$\mathrm{G}$ & 0.36 & $0.42 C_{\mathrm{R}}$ \\
$\mathrm{H}$ & 0.40 & $0.36 C_{\mathrm{R}}$ \\
$\mathrm{I}$ & 0.69 & $0.106 C_{\mathrm{R}}$ \\
$\mathrm{J}$ & 0.84 & $0.043 C_{\mathrm{R}}$ \\
$\mathrm{K}$ & 0.92 & $0.022 C_{\mathrm{R}}$ \\
$\mathrm{L}$ & 1.10 & $0.0 C_{\mathrm{R}}$ \\
\hline
\end{tabular}

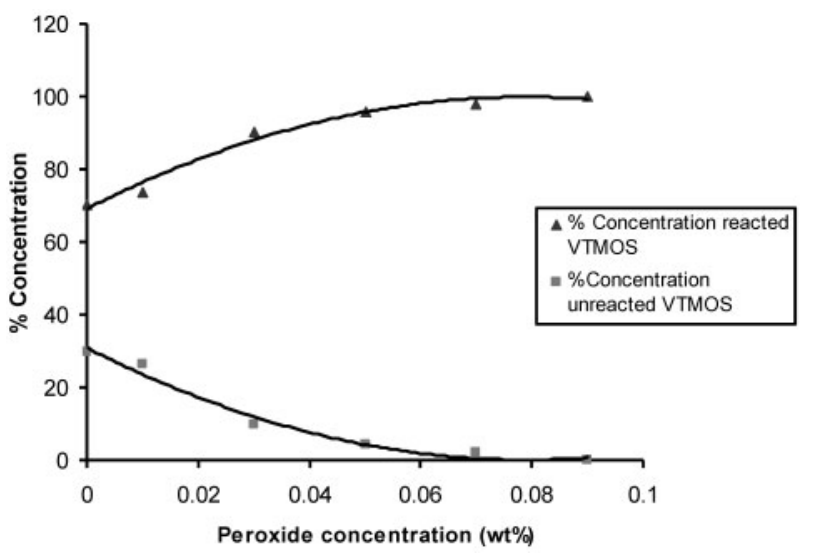

12 Effect of peroxide (wt-\%) on percentage concentration reacted and unreacted VTMOS

with varying VTMOS concentration. Figure 12 displays the relationship between the percentage concentrations of reacted and unreacted VTMOS with respect to peroxide concentration.

From this it can be concluded that as the concentration of VTMOS increased from 1.4-1.8 wt- $\%$ there is an increase in reacted VTMOS which can be explained by the fact that as the VTMOS increases there is an increase in the amount of VTMOS reacted and attached to the radical sites on the polyethylene backbone. These radical sites are generated prior to the peroxide decomposing and abstracting hydrogen atoms from the polymer backbone. A maximum is reached at a concentration of $1.8 \mathrm{wt}-\%$ VTMOS when the proportion of reacted monomer in the sample is found to be $99 \cdot 3 \%$.

This is then followed by a decrease in percentage reacted VTMOS with an increase in VTMOS concentration of 1.8 to $2 \cdot 2 \mathrm{wt}-\%$. The concentration of peroxide remains constant and excess unreacted VTMOS is present.

From the second series of samples where the peroxide concentration was varied from $0-0.09 \mathrm{wt}-\%$ the results show that there is an increase in reacted VTMOS until a plateau is reached. This can be explained by the fact that as the BTBB concentration increases there is an increase in radical sites generated on the polyethylene backbone; this in effect results in an increase in VTMOS reacting onto the sites hence causing an increase in the reacted VTMOS.

During the processing of the silane grafted polyethylene samples it should be taken into account that some silane is lost by volatilisation or by remaining on the sides of the barrel.

\section{Unsaturation content of reacted silane}

The degree of unsaturation is usually expressed in terms of the double bonds (vinyl group) in the VTMOS molecule. Using FTIR analysis the change in unsaturation content in both series of grafted samples was calculated. This was determined by measuring the area of the absorbance peak of the $\mathrm{CH}_{2}=\mathrm{CH}$ group in the VTMOS at $1009 \mathrm{~cm}^{-1}$. The ratio of this peak with respect to the polyethylene peak at $719 \mathrm{~cm}^{-1}$ (internal reference peak) was calculated.

In Fig. 13 it can be seen clearly how the unsaturation content of the VTMOS varies with increase in the VTMOS concentration. Also Fig. 14 shows the change in unsaturation in VTMOS with respect to peroxide concentration. These results are consistent with those in Figs. 11 and 12. 


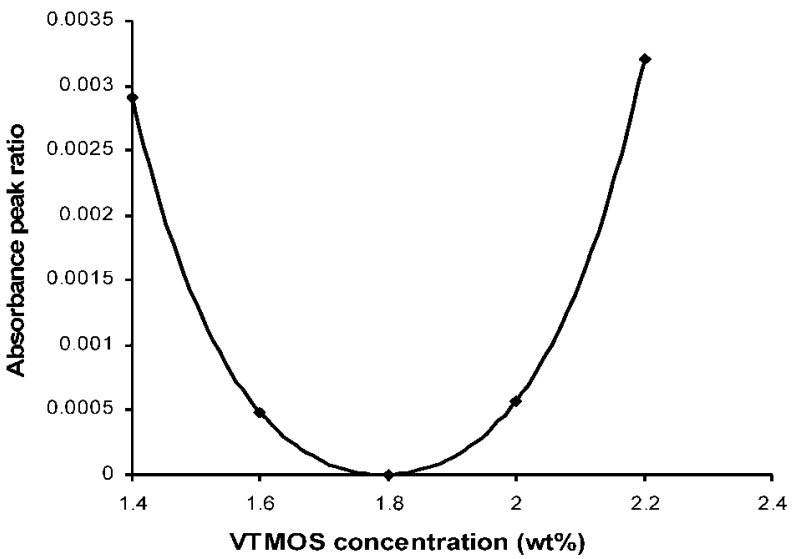

13 Effect of VTMOS (wt-\%) on unsaturation content

Figure 13 shows that initially as the VTMOS concentration increases there is a decrease in the unsaturation content of the VTMOS, this is because there is an increase in reaction taking place and since the reaction occurs via the vinyl group of the VTMOS monomer $\left(\mathrm{CH}_{2}=\mathrm{CH}-\mathrm{Si}\left(\mathrm{OCH}_{3}\right)_{3}\right)$ unsaturation decreases.

As the VTMOS concentration increases there is further increase in unsaturation as there is excess VTMOS that does not react with the polyethylene.

In the second series of grafted samples, where the peroxide concentration was increased there is a steady decrease in unsaturation content, because there is an increase in radical sites that have been generated, resulting in more silane grafting being produced.

\section{Conclusions}

From results obtained in this study it can be claimed that FTIR can be used to analyse quantitatively VTMOS grafted polyethylene material. Using FTIR spectroscopy it was confirmed that VTMOS is effectively grafted onto polyethylene showing variations in the materials structure with different concentrations of VTMOS and peroxide. Using the data calculated and the Beer-Lambert law a quantitative method was established. This was used to calculate the concentration of reacted and unreacted VTMOS in VTMOS grafted polyethylene samples processed on a twin screw extruder.

The results show that as the VTMOS concentration increased with constant peroxide concentration, a maximum percentage concentration of reacted VTMOS $(99 \cdot 3 \%)$ is reached at a concentration of $1.8 \mathrm{wt}-\%$ VTMOS and $0.05 \mathrm{wt}-\%$ peroxide. This does not represent a conversion figure, as some silane was lost during processing, and some reacted to produce low molar mass byproducts. With a continuous increase in VTMOS from 1.8 to $2 \cdot 2 \mathrm{wt}-\%$ a decrease in the $\%$ concentration of reacted VTMOS is observed. This can be explained by the fact that there is excess VTMOS that may not have reacted and therefore, the concentration of reacted VTMOS with respect to this excess decreases. However, on the other hand with an increase in peroxide concentration from 0 to $0.09 \mathrm{wt}-\%$ and constant VTMOS at $1.8 \mathrm{wt}-\%$ the results show that there is an increase in percentage concentration of reacted VTMOS, until a plateau is reached at which stage all the VTMOS has reacted in some form. These results are consistent with the unsaturation content measured at absorbance peak $1009 \mathrm{~cm}^{-1}$ on both series of grafted samples.

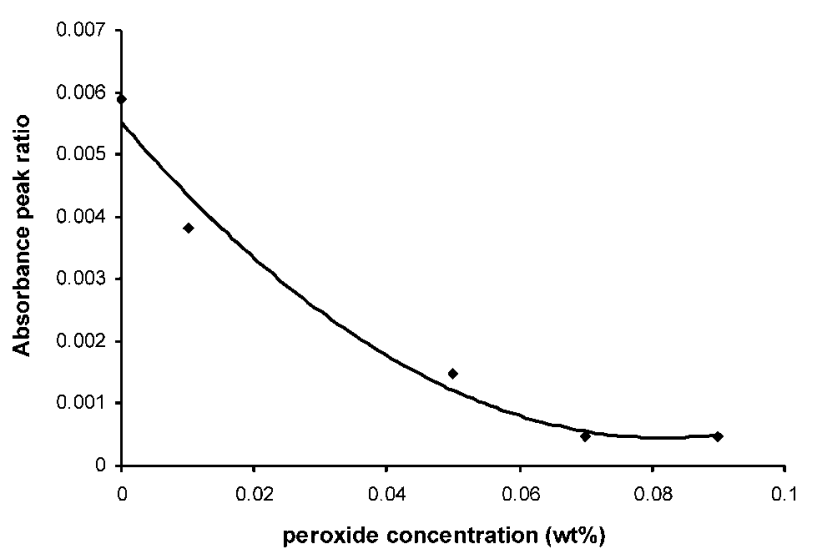

14 Effect of peroxide (wt-\%) on unsaturation content

This method has been proven to be applicable to any production VTMOS grafted polyethylene material processed on compounding extruders.

\section{Acknowledgement}

The reported study was part of a $\mathrm{PhD}$ research project sponsored by Micropol Ltd and Ineos, whose support is gratefully acknowledged.

\section{References}

1. C. Jiao, Z. Wang, Z. Gui and Y. Hu: Eur. Polym. J., 2005, 41, 1204-1211.

2. S. Ultsch and H.G. Fritz: Plast. Rubber Process Appl., 1990, 13, (2), $81-91$.

3. M. P. Munoz, P. M. D. Vargas, M. M. Werlang, I. Valeria, P Yoshida and R. S. Mauler: J. Appl. Polym. Sci., 2001, 82, 3460-3467.

4. H. G. Scott: US patent no. 3646155, 1972.

5. B. A. Sultan and M. Palmlof: Plas. Rubber Compos. Process. Appl., 1994, 21, (2), 65-73.

6. H. G. Scott and J. F. Humpries: Mod. Plast., 1973, 50, 82.

7. B. Thomas and M. Bowrey: Wire. J., 1977, 10, 88 .

8. D. Munteanu: Polymer, 1985, 49, 479-509.

9. P. Swarbrick, W. J. Green and C. Maillefer: US patent no. $4117195,1978$.

10. H. Huang, H. H. Lu and N. C. Liu: J. Appl. Polym. Sci., 2000, 78, $233-1238$.

11. J. A. McCormick, J. R. Royer, C. R. Hwang and S. A. Khan: $J$. Polym. Sci. B, 2000, 38B, 2468-2479.

12. M. Spencer, J. S. Parent and R. A. Whitney: Polymer, 2003, 44, 2015-2023.

13. Y.-T. Shieh, J.-S. Liau and T.-K. Chen: J. Appl. Polym. Sci., 2001, 81, 86-196.

14. K. E. Oliphant, K. E. Russell and W. E. Baker: Polymer, 1995, 36, (8), 1597-1603.

15. R. Anderlik and H.G. Fritz: Int. Polym Process, 1992, V11, 3.

16. T. Hjertberg, M. Palmlof and B. A. Sultan: J. Appl. Polym. Sci., 1991, 42, 1185.

17. Y.-T. Shieh and C.-M. Liu: J. Appl. Polym. Sci., 1999, 74, 3404-3411.

18. Y.-T. Shieh and T.-H. Tsai: J. Appl. Polym. Sci., 1998, 69, 255-261.

19. A. K. Sen, B. Mukherjee, A. S. Battacharyya, P. P. De and A. K Bhowmick: J. Appl. Polym. Sci., 1992, 44, 1153-1164.

20. C. Rosales, R. Perera, M. Ichazo, J. Gonzalez, H. Rojas, A. Sanchez and A. D. Barrios: J. Appl. Polym. Sci., 1998, 70, 161-176.

21. M. P. Munoz, M. D. Vargas, M. M. Werlang, I. Valeria, P. Yoshida and R. S. Mauler: J. Appl. Polym. Sci., 2001, 82, (14), 3460-3467.

22. J. A. McCormick, J. R. Royer, C. R. Hwang and S. A. Khan: $J$. Polym. Sci. B, 2000, 38B, 2468-2479.

23. C. Jiao, Z. Wang, Z. Gui and Y. Hu: Eur. Polym. J., 2005, 41, 1204.

24. S. M. S. Jamaludin, M. R. Nor Azlan, M. Y. Ahmad Fuad, Z. A. Mohd Ishak and Ishiaku: US Polym. Test., 2000, 19, 635-642.

25. W. K. Wong and D. C. Varrall: Polymer, 1994, 35, 5447-5452.

26. Y. T. Shieh, J. S. Liau and T. K. Chen: J. Appl. Polym. Sci., 2001, 81, 186

27. F. Precopio: Electr. Insul. Mag., 1999, 15, (1), 23-25. 